\title{
The Influence of Interlocked Employment-Family Trajectories on Retirement Timing
}

\author{
Ignacio Madero-Cabib ${ }^{1,2}$, Jacques-Antoine Gauthier ${ }^{1,2}$, and Jean-Marie Le Goff ${ }^{1,2}$
}

\author{
1. LIVES Research Centre, Université de Lausanne, Lausanne, Switzerland \\ 2. Life Course and Inequality Research Centre, Université de Lausanne, Lausanne, Switzerland
}

\begin{abstract}
How are employment and family experiences simultaneously linked to the timing of retirement? Based on a life course perspective, this article aims to understand the way in which different work and family statuses accumulated throughout adult life, lead to early, on-time, or late withdrawals from the labor market. We focused on Switzerland, a country characterized by a liberal and flexible pension structure that provides widespread institutional mechanisms for both early and late retirement. Using longitudinal methods such as multichannel sequence analysis and event history analysis, we have created types of interlocked employment and family trajectories from age 20 to 57 , and estimated their effects on the risk of retirement after age 58. The data come from the retrospective survey SHARELIFE, focused on ageing topics. The results show particularly that whereas early and "on-time" retirement is not likely for individuals - mostly women - with trajectories characterized by housework responsibilities, part-time jobs, and investments only in the public pension fund, late retirement is associated with the absence of a partner's financial support. In the conclusion, we argue that the Swiss retirement institution should consider alternative mechanisms to offer more balanced retirement opportunities to its citizens, especially to those following less advantaged employment-family trajectories.
\end{abstract}

Currently in advanced societies the timing of the transition to retirement is becoming particularly controversial due to different pension reforms aimed at delaying the moment at which people retire (Reynolds, Farrow, \& Blank, 2012). In recent decades, especially during the 1980s, early withdrawals from the workforce in most European countries were encouraged to compensate for low employment rates among older people. To this end, the minimum state pension age to receive public pensions was reduced, and occupational and private pension enterprises were allowed to offer financial incentives to stop work around age 60 (van Oorschot \& Jensen, 2009).

However, from the 1980s, the emergence in Europe of declining birth rates associated with an ageing population, combined with disruptions in the financial stability of public spending and private pension funds, fostered the need to discourage early retirement. By contrast, measures to encourage on-time or even late retirement started to be promoted (Fraccaroli \& Deller, 2015; Hamblin, 2010; Hanel, 2010). Indeed, 2012 was declared the European Union Year for Active Aging, and in the same year, the OECD suggested gradually increasing state pension ages (OECD, 2012). In both cases the aim was to promote various social policies toward the career continuity of older workers.

In this international frame Switzerland appears as an illustrative example of a country that from the 2000s has increasingly been creating institutional procedures such as financial penalties for early retirement or financial benefits for late retirement, in order to foster a longer working life. Moreover, as we describe below, the liberal character of the Swiss pension institution means that in this country individuals have multiple routes to leave the labor market at any time (Cattacin, 2006; Tabin, 2002; Tabin, Frauenfelder, Togni, \& Keller, 2008). However, the emergence of institutional procedures aimed at reversing retirement timing patterns, and also the presence of a liberal pension institution offering different retirement options, do not mean that workers in Switzerland confront the timing of retirement in a socially homogeneous way. Based on a life course approach, in this article we seek to analyze how adult life trajectories influence the timing of retirement: before, after, or at the state pension age.

We consider the life course approach given that it offers an alternative to classical retirement studies which focus on the impact of snapshot characteristics of individuals just before retirement. The life course perspective not only emphasizes these time-specific life characteristics but also allows us to understand how, during the life course, long-term and cumulative experiences in different domains may impact the retirement transition (Kohli, Rein, Guillemard, \& Van Gunsteren, 1991).

Here, the notion of cumulative advantage or disadvantage (CAD) is crucial for a theoretical understanding of the great relevance of path

(C) The Authors 2015. Published by Oxford University Press. For permissions please e-mail: journals.permissions@oup.com

Correspondence concerning this article should be addressed to Ignacio Madero-Cabib, LIVES Research Centre, Université de Lausanne, Room 5609, Bâtiment Géopolis, CH-1015 Lausanne, Switzerland. E-mail: ignacio.maderocabib@unil.ch 
dependencies across individual life courses on late-life statuses. The $\mathrm{CAD}$ approach recognizes social differences between individuals as a consequence of gradual cumulative experiences along life course trajectories that can be reinforced or mitigated by social policies (Elder, 1995; Dannefer, 2003; DiPrete \& Eirich, 2006). Put in an illustrative way, small inequalities in educational background, family responsibilities, citizenship status, and occupational statuses tend to accumulate over time and might produce socially differentiated transitions later on, for example, at the time of retirement.

In this research, we focus on two types of adulthood trajectories: employment and family paths. This is because of the wide recognition in life course research of the influence that dynamics in the family and labor systems have in individuals' late life (Madero-Cabib, 2015; Madero-Cabib \& Kaeser, in press). Additionally, life course scholars acknowledge the strong interrelation of work and family life courses in current societies. Illustrative of the strong coupling between these two domains is, for instance, the master status hypothesis (Krüger \& Levy, 2001), which suggests that life courses are divided mainly by the relationship manifested between paid work and family work. In addition, the notion of differentiated life course of Elder (1985) presents life courses as a competition essentially between family and work roles.

At national and international level, we find various studies aiming to understand the impact on retirement timings of early life experiences either in the family or in the work domain (Damman, Henkens, \& Kalmijn, 2011; Finch, 2014; Hank \& Korbmacher, 2013; MaderoCabib, 2015; Raymo, Warren, Sweeney, Hauser, \& Ho, 2011). However, considering the strong interrelation of family and work lives in current societies, instead of studying the role of occupational and family paths separately, in this study we evaluate the influence of interlocked employment-family trajectories on retirement timing variation.

Therefore, the main objective of this article is to investigate how simultaneous experiences in the employment and family domains, accumulated during the entire adult life, influence the timing of workers' retirement in Switzerland. This article is organized in six sections. First, we describe particular aspects of the retirement context in Switzerland. Second, in the theoretical background section, we mention previous research on the influence of employment and family characteristics on retirement timings, and we set out our research hypotheses. Third, we introduce the retrospective survey of health, ageing and retirement in Europe (SHARELIFE), and the longitudinal methods used in this study. Fourth, the results of an exploratory survival analysis, a multichannel sequence analysis, and discrete time models are presented. The fifth section discusses the research hypotheses, while the last section proposes some conclusions and further perspectives.

\section{WHY FOCUS ON RETIREMENT TIMINGS IN SWITZERLAND?}

One first appealing aspect of the Swiss case is the liberal focus of its social assistance. International literature describes accurately the liberal basis of the Swiss state. For instance, using the three-axis classification of welfare states, that is, decommodification, social stratification, and employment, made by Esping-Andersen (2011) and deepened by Scruggs and Allan (2006), Switzerland shows clear characteristics of a liberal country, considering the modest universal transfers, and also the great relevance of private social assistance.
Similarly, the national literature also classifies Switzerland as a liberal state (Cattacin, 2006; Tabin, 2002; Tabin et al., 2008). Indeed, these studies suggest that the welfare focus in the Swiss political domain was installed rather late compared with other European nations. Put concretely, in the period of the "30 glorious years" (19451975), whereas welfare state policies increasingly existed in many Western European countries, in Switzerland "national welfare" was mainly managed by the economy through salaries that assured at least a minimum life standard (Cattacin, 2006). Simultaneously, religious and voluntary organizations were responsible for particular assistance procedures aimed especially at poor individuals (Tabin et al., 2008).

During the 1970s and 1980s, Switzerland confronted a period of changes in the social assistance paradigm, adopting traditional welfare state policies. The crucial variations included, first, the extension of social assistance rights to the entire population and, second, the exclusive role of the state in regulating such rights (Tabin et al., 2008). This new perspective of the Swiss state as guarantor of social benefits was framed in a process described as the professionalization of social assistance (Cattacin, 2006). Among the relevant initiatives of this new regime were unemployment insurance, the occupational pension fund, and accident insurance.

Nevertheless, as mentioned, these welfare assistance procedures have been framed in a Swiss state traditionally marked by its liberal character, which concretely implies that the state individualizes the costs and risks of having public systems of retirement, unemployment, or health disability (Esping-Andersen, 2011). An illustrative example in order to better understand the liberal focus of the social assistance in Switzerland is provided by the retirement institution.

In this country, the retirement institution is organized into three different pension funds or pillars. The first pillar is the old-age and survivors insurance (assurance-veillesse et survivants, or AVS), which is a mandatory universal insurance with the aim of providing a basic income in old age. The AVS pension can be drawn at state pension age, currently defined as 64 for women and 65 for men. This pension pillar is rooted in the "pay-as-you-go" (PAYG) pension logic, according to which active people finance the pensions of retirees, and the state is the exclusive administrator of funds (Calvo, Bertranou, \& Bertranou, 2010). The PAYG pension logic traditionally exists in conservative corporatist states.

The second pillar is the occupational pension planning (prévoyance professionnelle). This fund is devoted to employees and civil servants earning more than 20,880 Swiss Francs per year (this is about $\$ 21,771$ or $€ 20,370$ ). According to the Swiss Federal Office of Statistics (OFS), the central aim of this fund is to complement the AVS pillar in order to cover at least $60 \%$ of the final salary of workers (OFS, 2014). The occupational pension pillar can be called on officially from age 58. Finally, the third pillar is a private reserve accumulated by a person in a bank or insurance company fund. It is not compulsory, in contrast to the two other pillars, and is often used by the self-employed-who cannot participate in the second pillar-although salaried people can also contribute to private programmes (Dorn \& Sousa-Poza, 2004a, 2004b). Both the second and third pillars are embedded in the "individual retirement account" (IRA) pension logic, in which personal savings and contributions support the financing, and the management is completely private. The IRA pension logic is usually present in liberal states (Calvo et al., 2010). 
Considering this description of three pillars, one could argue that the Swiss pension structure does not have a strictly liberal focus since it operates according to the pension distribution logics of liberal and conservative corporatist states, that is, IRA and PAYG logics, respectively. But in PAYG systems the risks of losing and not continuously contributing to public pensions are normally assumed by the state (Calvo et al., 2010). However, in the AVS pension fund-i.e., the seeming PAYG pillar in Switzerland-it is the individuals who assume such risks, since if they stop contributing they can face a reduction of an average of $2.3 \%$ per year over the accumulated savings (OFS, 2012a; Although it is mandatory to contribute to the AVS pension fund for every active and nonactive individual, there are some cases where people are not able to contribute.). Besides, another paradoxical element of the AVS pension fund apparently being based on a PAYG logic is that its financing is supported by individual contributions and not by the regular taxes that must be paid additionally to the state.

As some research results suggest, this pension institution, in which the state appears as a mere administrator of individual contributions, aims at enlarging the personal decision to invest as much as a person wants to invest for his/her elderly life as well as to retire whenever he/she wants to retire (Cattacin, 2006). If this is so, this liberal schema should provide multiple retirement routes allowing people to retire at any time. We examine this flexibility later, but now turn to the mechanisms currently provided for early and late retirement.

Several mechanisms may foster early retirement in Switzerland. The bottom age limits set by the second and the third pension funds at age 58 and 60, respectively (OFS, 2011), which are below the state pension age; the existence of financial early retirement bridges (Roduit, 1993); unemployment and disability insurance; and complementary public pension provisions for assuring minimum pension amounts (OFS, 2012 b), are examples of early retirement routes.

Yet in Switzerland, as in most European countries (Fraccaroli \& Deller, 2015; Hamblin, 2010; Hanel, 2010), an increasing ageing population, associated with disruptions in the financial stability of public spending and in private pension funds, are stimulating the development of incentives for late retirement at both political and market levels. The active ageing mechanisms promoted in Switzerland (It is relevant to indicate that the measures for early as well as late retirement did not necessarily exist for the oldest cohorts in Switzerland. Consequently a strong age effect in terms of retirement timing is expected.) are actualized through options for accumulating public pension funds beyond the state pension age (up to age 69 for women and 70 for men), financial benefits in the frame of the occupational pension fund in the case of late retirement, financial penalties for early retirement and financial exemptions for late retirement provided by the public pension fund, and also training policies in different sectors of the Swiss economy aimed at a longer working life (Kuehni, Rosende, \& Schoeni, 2013; OFS, 2012b, 2012c, 2012d).

Thereby, the liberal character of the Swiss pension structure, and the flexible mechanisms in terms of retirement timings that the corresponding institutions offer, call for a focus on retirement dynamics in this country. As aforementioned, it is noteworthy, nevertheless, that the fact that this pension structure provides institutional procedures to retire either early or late does not mean that everyone has the same opportunity to retire at any time.

\section{THEORETICAL BACKGROUND AND RESEARCH HYPOTHESES}

As mentioned, considering the strong interdependence of work and family life in current societies (Elder, 1985; Krüger \& Levy, 2001) as well as the impact of the accumulated experiences in these two domains on the retirement process (Damman et al., 2011; Fasang, Aisenbrey, \& Schömann, 2013; Finch, 2014), in this study, we evaluate the influence of interlocked employment and family trajectories on retirement timing variation.

In order to construct employment and family trajectories we bear in mind previous life course research on the retirement topic (Damman et al., 2011; Madero-Cabib, 2015; Raymo et al., 2011). In particular, to analyze employment trajectories we focus on the statuses activity rate (i.e., out of the labor market, full-time job, and part-time job) and pension investments (i.e., investments in the public, occupational, and private pension funds).

As regards activity rate, previous research shows that working in full-time jobs increases the chances of taking early retirement due to the possibility of investing enough pension funds, while part-time jobs would be rather related to late retirement given their association with insufficient savings for elderly life (Finch, 2014). We therefore hypothesize that the longer the periods in full-time positions the higher the probability of retiring early, while part-time jobs will lead to "on-time" or late retirement, even if the part-time contract is preceded or succeeded by full-time contracts (Hypothesis 1).

Moreover, concerning investment in Swiss pension funds, various studies indicate that individuals who make significant and continuous contributions to public and private pension funds during their careers retire early more frequently (Gaillard, Bilger, Candolfi, Chaze, \& Flückiger, 2003; Dorn \& Sousa-Poza, 2004a). As we have explained, in particular the pension pillars that are dependent on own income-i.e., the occupational and the private pension plans - represent important sources of pension savings in Switzerland (Bonoli, 2006); as a consequence, we hypothesize that workers who especially did not contribute to these two pension plans are more likely to retire late (Hypothesis 2).

It is worth mentioning that both activity rate and pension investments are employment statuses highly dependent on workers' gender (Finch, 2014; Hank \& Korbmacher, 2013). Research results show that men have more continuous careers than women and consequently more opportunities to invest in different pension funds. This occurs mainly because women are more likely to interrupt their occupational trajectories due to domestic/family responsibilities (Han \& Moen, 1999; Raymo et al., 2011). Kuehni and colleagues (2013) point to the fact that, specifically for Switzerland, this gender inequality is a consequence of the way in which the Swiss pension funds are organized: they favor financially stable occupational status, that is, full-time jobs and continuous careers from the end of education up to retirement, which typically fit the model of the qualified male breadwinner. We can thus hypothesize that types of occupational trajectories characterized by full-time employment and investments in public and private pensions will be mainly composed of male populations (Hypothesis 3).

Furthermore, to construct types of family trajectories we focus on parenthood and marital statuses. Considering first the parenthood status, as Swiss and international literature illustrate, one of the main family determinants - mostly for women - of postponing the retirement until or beyond the state pension age corresponds to the childcare during the early family phase (Hank \& Korbmacher, 2013; 
Le Feuvre et al., 2014; Madero-Cabib, 2015). This is usually explained by the fact that individuals who spend long periods out of the labor force due to child caring need to continue working to cover pension investment gaps and consequently to have enough pension funds for elderly life (Fasang et al., 2013). Our first hypothesis in relation to the parenthood status is that, especially for women, family trajectories characterized by childcare-or "family unpaid work"-will lead to late retirements regardless of whether this childcare period is preceded or succeeded by strong attachment in the labor market (Hypothesis 4). Moreover, considering the male-breadwinner context that historically has existed in Switzerland, we hypothesize that for a great proportion of men and women in the study sample, we will find similar parenthood formation, but associated with opposite labor force participation (Hypothesis 5).

Examining particularly the effect of marital status, some studies point out that when a person's partner is already inactive before the state pension age, that person is also more likely to retire earlier (Dorn \& Sousa-Poza, 2004b; Gaillard et al., 2003). Moreover, divorced individuals tend to retire late from the labor market, partly as a consequence of the loss of the financial contribution of their former partners, which however occurs mostly in the case of women (Cherlin, 2009; Madero-Cabib, 2015). Likewise, individuals who remained single after confronting divorce are more likely to postpone retirement beyond the legal age than those who remarry (Finch, 2014). Hence, considering the studies mentioned, our sixth hypothesis is that, independently of their employment trajectory, people who are divorced or who never married will be more likely to retire late than individuals who married and remained in this marital status (Hypothesis 6).

\section{METHODS}

\section{Data}

The data we use to test the research hypotheses comes from the survey of health, ageing and retirement in Europe (SHARE). We focus on its third wave named SHARELIFE, which has a retrospective design. SHARELIFE is a cross-national and longitudinal study of individuals aged 50 years and older in different European countries. It was performed between 2008 and 2009. The main reason to choose the SHARELIFE survey corresponds to its very rich information regarding several topics over the course of people's lives, including among others family composition, occupation characteristics, retirement, and health care (Schröder, 2011). The process of collecting data for SHARELIFE was based on probabilistic sampling and face-to-face interviews using life history calendars (LHC) that helped respondents remember their past life and chronologically organize the various episodes of their trajectories (Schröder, 2011). Specifically, by means of LHC, participants were asked to recall events in different life domains on a yearly basis. Also, in the LHC, various national and world events that occurred during the lives of participants were presented, which could help to better remember their own life events.

Our analysis sample concerns all persons included in the Swiss section of SHARELIFE who were working at age 58, and who might have retired when they were interviewed (674 persons, 397 men and 277 women). In this way, we can first reconstruct whole employmentfamily life courses until age 57, and secondly follow their labor careers year-by-year from age 58 until the age of retirement. The reason why we focus on age 58 as the threshold is that this is currently the minimum early retirement age in the frame of the occupational pension plan, and also that people start to retire considerably from that age (see the survival analysis in the Results section).

In relation to the gender composition of the study sample, it is relevant to mention that whereas in the study sample $(N=674) 58.7 \%$ are men and $41.3 \%$ women, in the Swiss sample of SHARELIFE $(N=1,296) 45.9 \%$ are men and $54.1 \%$ women. The gender gap between the Swiss sample in SHARELIFE and the study sample composed by people working at age 58, fits the official statistics of EuroStat data, which illustrate that women aged 60-64 during 1996 and 2012 did not exceed the $40 \%$ in the average employment rate, although they experienced a growth in this regard in the last decade (Figure 1).

Moreover, one issue to bear in mind regarding the Swiss component of the SHARE survey is that the household response rate is only $38.8 \%$, as is common in Swiss surveys conducted through faceto-face interviews (Stähli \& Joye, 2013). Traditionally, low household response rates are associated with possible sample selectivity on socioeconomically advantaged persons. However, a recent study on respondent and nonrespondent samples by Stäheli and Joye (2013) indicates that, in Switzerland, "the comparisons with population data did not bring to light significant differences between respondents and nonrespondents, except for nationality, non-nationals being underrepresented as in most surveys (...) Such differences were supposed to lie more on the attitudinal level than on sociodemographics" (Stähli \& Joye, 2013, p. 18). Moreover, a clearly positive aspect of the Swiss sample in SHARE is that it has one of the highest individual response rates within households (i.e., 87.8\%).

As regards the management of the issue of nonresponse rate in this study, the approach followed was the one indicated by the SHARE administrators, namely to adjust the results by calibrated weights (Deville \& Särndal, 1992). As mentioned in SHARE Guide 2.5.0, calibrated weights provide weights that are as close as possible to the original sampling design weights while also respecting a set of known population totals (Deville \& Särndal, 1992). Therefore, all the analyses deployed below are weighted using calibrated weights.

\section{Measures}

\section{Dependent variable}

The dependent variable of the study is retirement timing, which has been disaggregated into three different categories, namely "early," "ontime," and "late" retirement. It is important to highlight that we constructed these three variables taking into consideration the fact that the state pension age is different for women and men and that this difference has changed over time. Specifically, we used the following strategy: in the case of men, given that the state pension retirement age is 65 , early retirement means retirement at age 64 or less, while on-time retirement refers to withdrawals at age 65 , and late retirement at age 66 or later. In the case of women, the pension retirement age for those born before 1938 is 62, for those born between the years 1939 and 1941 it is 63, and for those born after 1942 it is 64 (Candolfi \& Chaze, 2008). Therefore, we decided to define early, on-time, and late retirement according to each respondent's age.

Timing of retirement is assessed according to a self-reported question about the reasons for leaving a job. When people chose the reason "for retiring," we observed the year in which the person left the job in question, and then we determined whether the person retired 


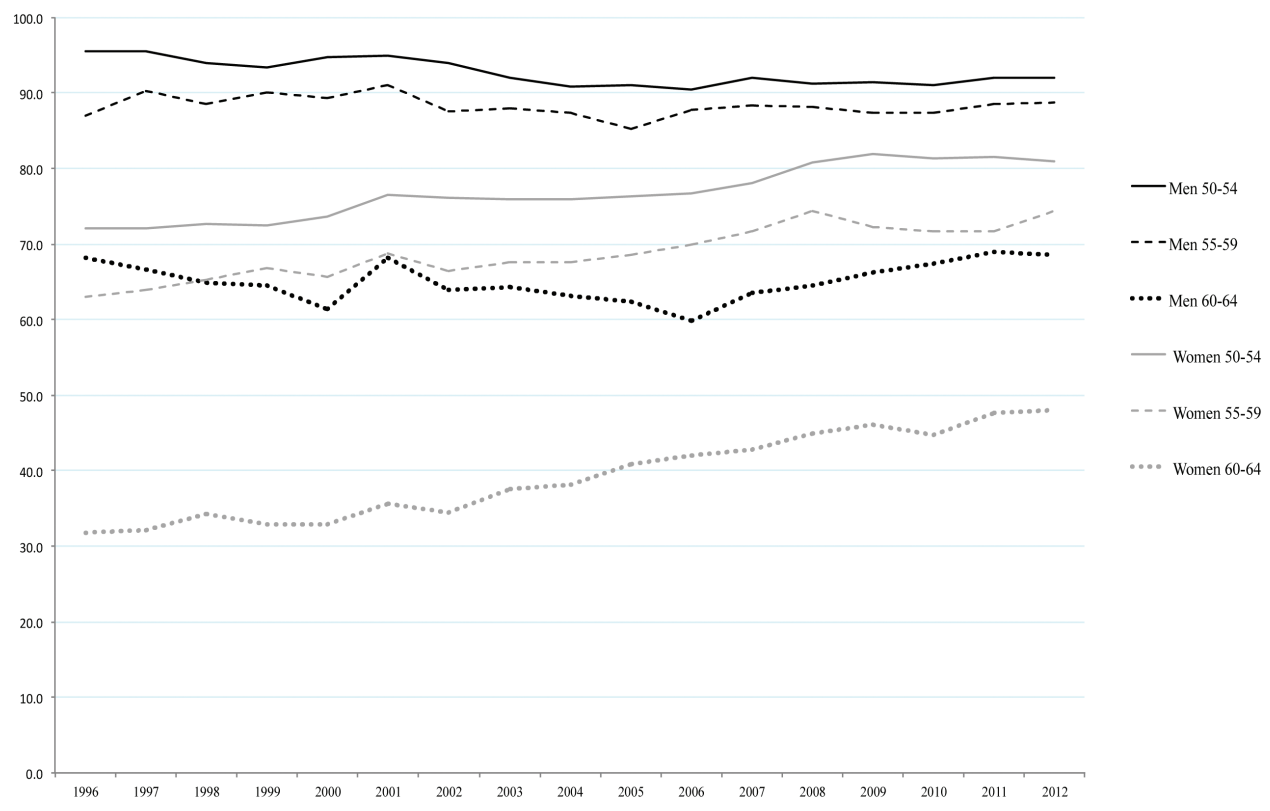

Figure 1. Employment rate by gender and age class in Switzerland between years 1996 and 2012. Source: epp.eurostat.ec.europa. eu/portal/page/portal/employment_unemployment_lfs

early, on-time, or late. In order to be sure that people were effectively retired we checked another question that asked whether the respondent receives or does not receive pension benefits - a question that only retirees could answer.

Here it is worth mentioning that, in SHARELIFE, once a respondent reports the retirement event they are excluded from further labor observations. As a consequence, we are not allowed to observe neither whether retirees continue working, nor whether they have access to a work income after starting to receive retirement benefits. In this sense, we acknowledge that this way of analyzing retirement can be seen as restricted considering both the bridge employment literature and the retirement-as-a-process literature, which precisely problematize those aspects of the retirement transition (Beehr \& Bennett, 2015; Gobeski \& Beehr, 2009; Wang, 2007; Wang, Zhan, Liu, \& Shultz, 2008). However, we are also aware that this is the more accurate way to measure the transition to retirement with SHARELIFE data.

\section{Covariates}

Our key covariates are types of interrelated employment and family trajectories across the life course. Employment and family trajectories are measured as longitudinal sequences in yearly intervals from age 20 to 57. Employment trajectories were specified using seven states based on a combination of the statuses activity rate and pension investments: (1) "out of the labor force," which includes education, housework, and unemployment, (2) "full-time employment, no pension investments," (3) "full-time employment, investment public pension fund," (4) "full-time employment, investments public and other pension funds," (5) "part-time employment, no pension investments," (6) "part-time employment, investments public pension fund," and (7) "part-time employment, investments public and other pension funds." The reason why we did not devise categories relating to investments made in the three different pension funds is that there were few people investing pension savings simultaneously in all of them. By contrast, almost everyone invested in the AVS pension fund. Information about pension investment comes also from a self-reported question.

Furthermore, to construct family trajectories we considered six states created from a mixture of parenthood and marital statuses: (1) "single," which includes both individuals without children and a small proportion of single people with children, (2) "married, no children," (3) "married, children," which implies that children are living at parental home, (4) "divorced," which includes people with and without children, (5) "departure of children from parental home," and (6) "divorced plus departure of children from parental home." The status "single" includes very few reported unmarried relationships. The marital condition in the status "departure of children from parental home" is married in almost all the cases. Finally, we do not distinguish between divorced with and without children, since divorce without children occurred very rarely in our study cohorts.

In addition to the employment and family trajectories we include gender, age, education, financial hardship periods, health problem periods, income, and country of origin as control covariates. Age was measured every year after age 58. Income was measured as the first monthly income in every job after age 58. Age and income are thus time-varying covariates. Education was measured according to the International Standard Classification of Education of 1997 or ISCED-97 codes (UNESCO, 2006). The proportion of missing values in covariates represents at most $10 \%$ of the sample. Table 1 presents weighted univariate frequencies of the key and control covariates used in this research (Types of interrelated employment and family trajectories are described in depth in the Results section.).

\section{Analytic Strategy}

We applied two quantitative techniques largely used in life course studies, namely event history analysis and multichannel sequence analysis. Event history analysis is a method designed to investigate 
Table 1. Covariates

\begin{tabular}{|c|c|c|}
\hline Covariates & & Operationalization and Weighted Distribution \\
\hline \multirow[t]{6}{*}{ Key covariates } & Full-time worker, AVS+ / children family & 1: Belonging (28.6\%), 0: Not belonging (71.4\%) \\
\hline & Out of labor force \& part-time worker, AVS+ / children family & 1: Belonging (27.5\%), 0: Not belonging $(72.5 \%)$ \\
\hline & Full-time worker, AVS / children family & 1: Belonging (16.8\%), 0 : Not belonging $(83.2 \%)$ \\
\hline & Full-time and part-time workers, AVS / divorced & 1: Belonging (7.7\%), 0: Not belonging $(92.3 \%)$ \\
\hline & Full-time worker, AVS+ / divorced & 1: Belonging (7.4\%), 0: Not belonging $(92.6 \%)$ \\
\hline & Full-time worker, AVS+ / single & 1: Belonging (12.0\%), $0:$ Not belonging $(88.0 \%)$ \\
\hline \multirow[t]{13}{*}{ Control covariates } & Gender & $1: \operatorname{Men}(58.7 \%), 0:$ Women $(41.3 \%)$ \\
\hline & Age & Continuous and time-varying covariate \\
\hline & Education & Educational level ISCED 1 (11.6\%) \\
\hline & & Educational level ISCED 2 (19.1\%) \\
\hline & & Educational level ISCED 3 (32.0\%) \\
\hline & & Educational level ISCED 5 (31.9\%) \\
\hline & & NA in educational level ISCED (5.5\%) \\
\hline & Financial hardship periods & 1: Yes $(30.8 \%), 0:$ No $(69.2 \%)$ \\
\hline & Ill-health periods & $\begin{array}{l}\text { 1: One or more periods of ill-health }(12.0 \%), 0: \text { No } \\
\text { periods of ill-health }(88.0 \%)\end{array}$ \\
\hline & Log income & Continuous and time-varying covariate \\
\hline & Country of origin & $\begin{array}{l}\text { 1: Switzerland }(82.1 \%), 0: \text { Other countries }(14.5 \%), \\
\text { NA in country of origin }(3.4 \%)\end{array}$ \\
\hline & Marital status at retirement & $\begin{array}{l}\text { 1: Single (8.8\%), 2: Married (72.3\%), 3: Divorced } \\
\quad(10.9 \%), 4: \text { Widowed }(7.6 \%)\end{array}$ \\
\hline & Employment status before retirement & 1: Full-time ob (71.0\%), 2: Part-time job (29.0\%) \\
\hline
\end{tabular}

the probability—or the risk-of experiencing_or surviving to-certain events over the life course, taking into account the impact of different covariates (Mills, 2011). We specifically use two extensions of event history models. First, we use an exploratory survival analysis to globally analyze the timing of retirement. This technique provides the probability of surviving to particular events for individuals liable to face them, for instance in our study, people aged from 58 who might retire at 58 or people aged 59 who might retire at 59 , etc.

Secondly, in order to study separately the probability of experiencing early, on-time, or late retirement, regarding the influence of covariates, we devised weighted discrete time models (Allison, 1982). As Mills (2011) has pointed out, one of the major reasons to use this extension of event history analysis relates to the possibility of examining longitudinally how both time-fixed and time-varying covariates impact the risk of occurrence of an event along the life course. Discrete time models are thus based on the notion of the risk of experiencing an event as age passes, and not on the frequency or the density of distribution of that event. Moreover, as the time scale in SHARELIFE is by year, discrete time models are preferred here to continuous time models.

In particular, the discrete variable of this study corresponds to the conditional risk of experiencing (or not experiencing) a withdrawal from the labor market early, on-time, or late after age 58. Conditional risk refers to the risk of experiencing an event at a given age, given that the individual had not experienced this event before. Therefore, in the present study the analyzed risk consists in the conditional probability to retire at a certain age, given that people did not retire before.

Three weighted discrete time models were constructed, one for early retirement, another for on-time retirement, and another for late retirement. In each discrete time model the risk of retirement is estimated by the number of retirements observed 1 year divided by the number of persons submitted to the risk of retirement, that is, people who do not retire yet. Hence, in the first discrete time model, all persons in our sample are considered subject to the risk of early retirement (i.e., retirement under age 65 for men and under 62, 63, or 64 for women, depending on the birth cohort). The second model"on-time" retirement-comprises individuals who did not experience early retirement or were censored before the legal age (on the concept of censoring see Mills, 2011). Therefore, the population subject to the risk of on-time retirement is composed of individuals having the same age as the state pension age, and who will either retire at the state pension age or will continue working and retire later. The third modellate retirement - takes into account persons who experienced neither early nor on-time retirement; thus the starting age for the analysis of the risk of late retirement is the state pension age of retirement +1 . Thereby, if a man or woman retires late, he/she is taken into account in the models for early, on-time and late retirement. Here it is relevant to point out that since we studied the conditional risk to retire at certain age, discrete time models did not compare early retirement versus late retirement, or on-time retirement versus late retirement, or late retirement versus very late retirement, but for each regression, to retire versus not to retire at a given age.

On the other hand, to construct interlocked employment and family trajectories we use multichannel sequence analysis (MCSA) (Gauthier, Widmer, Bucher, \& Notredame, 2010), a recently developed extension of sequence analysis (Abbott, 1995). Sequence analysis is a technique that creates typologies of longitudinal patterns from sequences of life course events in domains such as family, education, politics, and occupation. To this end, this method analyzes the chronological order of the states that compose an individual trajectory in any 
domain, and then compares the similarity between all possible pairs of individual trajectories. Two persons are regarded as similar if they share, for instance, similar employment or a similar family trajectory. Multichannel sequence analysis is a method that analyses individual sequences not in specific domains, as sequence analysis does, but simultaneously in at least two social domains (Gauthier et al., 2010).

The output of both sequence analysis and multichannel sequence analysis is a pairwise distance matrix that summarizes the distance between the individual sequences. To calculate the distance between sequences we use optimal matching analysis, specifically setting constant the substitution costs of 2 and indel costs of half this uniform substitution cost of 1 (MacIndoe \& Abbott, 2004). We also calculate this pairwise distances matrix using the dynamic hamming distance (Lesnard, 2010) which specifies time-dependent substitution costs based on time-point specific transition probabilities between two sequence states. However, given that the clustering showed better cut-off criteria we retain optimal matching analysis for the final specification.

It is then possible to perform a cluster analysis on the resulting distance matrix, which allows homogeneous groups of sequences to be created, which, taken together, represent types of trajectories (Gauthier et al., 2010). To this end, we use particularly the Ward cluster analysis (Ward, 1963). Moreover, to determine the most appropriate number of clusters, we considered several cluster cut-off criteria, including the average silhouette widths (ASW) and point biserial correlation (PBC) (Studer, 2013). As Figure 1A indicates, they suggest that six clusters is an appropriated grouping with a maximum ASW of .27 and a maximum PBC of .57 (Studer, 2013). After six clusters both ASW and PBC tend to decrease.

All the calculations presented here are made using the $\mathrm{R}$ statistical software (R Core Team, 2012) along with the libraries svytable - for calculating univariate frequencies—svykm - for building exploratory survival analysis - and svyglm - for estimating discrete time models. These three libraries belong to the package survey (Lumley, 2013)

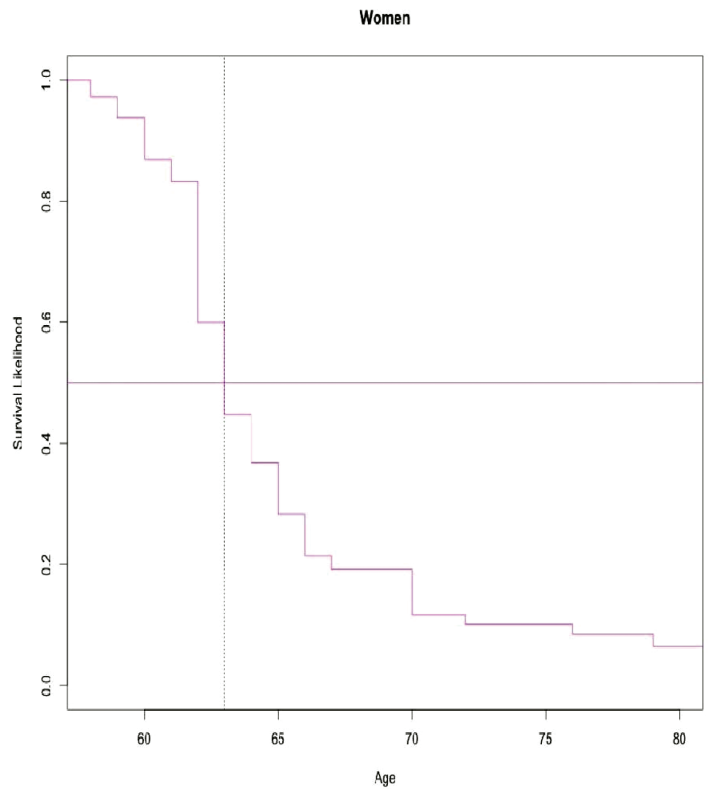

which was designed for the analysis of weighted data. Moreover, we used TraMineR for the multichannel sequence analysis (Gabadinho, Ritschard, Müller, \& Studer, 2011).

\section{RESULTS}

\section{Survival Analysis of Retirement}

In order to have a first overview of the current retirement timing tendencies in Switzerland, we start by presenting the results regarding the survival function of retirement by gender, that is, the probability of not experiencing such an event. The survival functions in Figure 2 show first that in Switzerland about $95 \%$ of both women and men retire before age 70 . Secondly, Figure 2 indicates that about $45 \%$ of women retire between age 62 and 64 , and about $35 \%$ of men retire at age 65 . This reveals that in Switzerland both for women and men the current retirement ages are moderately associated with the state pension ages, which also confirms a relative institutionalization of this transition. Finally, survival functions in Figure 2 reveal that about $90 \%$ of both women and men retire between the ages of 60 and 70 .

\section{Types of Interlocked Employment-Family Trajectories}

Figure 3 indicates the six types of employment-family trajectories as state distribution plots. The employment trajectory is displayed on the left-hand side and the corresponding family trajectory of the same persons in a type is displayed on the right-hand side. They show the proportion of people in a type in a respective sequence state, such as "out of the labor force" or "divorced," which are indicated by different colors. The size of the clusters reflects their respective size in the sample population. In each cluster the proportion of women and men is indicated.

In line with Hypothesis 5, the types that mostly compose the sample population (Types 1,2 , and 3 ) have a similar family trajectory of marriage and parenthood, but they are highly gendered in employment terms: whereas the types characterized by full-time employment

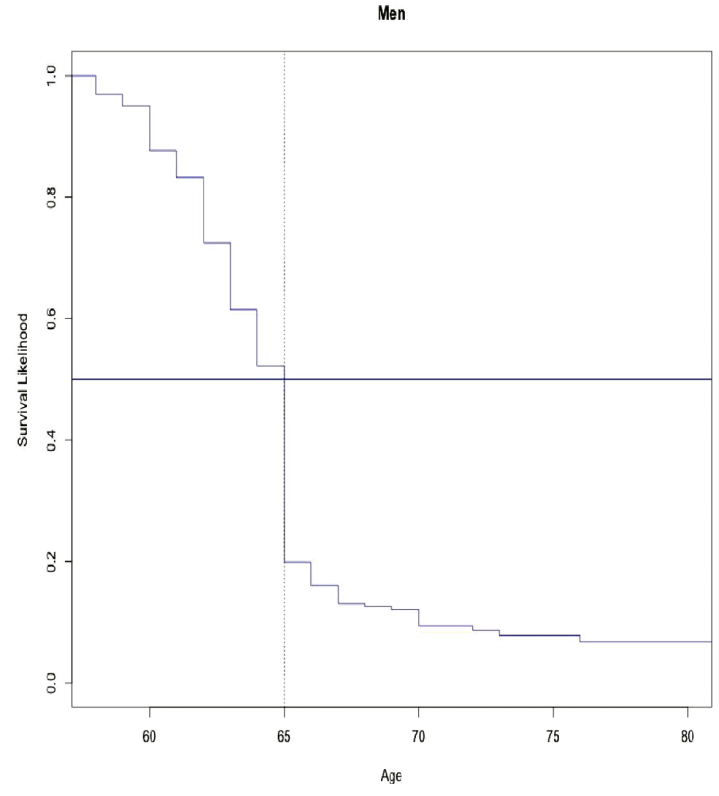

Figure 2. Survival functions of retirement for women and men in Switzerland. 
6) Full-time Worker, AVS+/ Single (12.0\%) Women: $47.4 \%$, Men: $52.6 \%$

5) Full-time Worker, AVS+/ Divorced (7.4\%) Women: $18.8 \%$, Men: $81.3 \%$

4) Full-Time and Part-Time Workers, AVS / Divorced $(7.7 \%)$ Women: $59.6 \%$, Men: $40.4 \%$

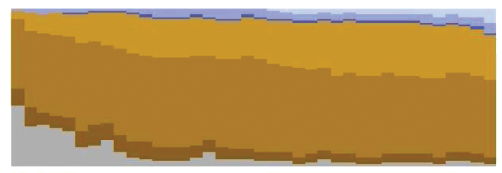

Full-time Worker, AVS / Children Family (16.8\%) Women: $15.4 \%$, Men: $84.6 \%$

2) Full-time Worker, AVS+/ Children Family (28.6\%) Women: $7.2 \%$, Men: $92.8 \%$

1) Out of the Labor Force \& Part-time Worker, AVS+ / Children Family (27.5\%) Women: $90.8 \%$, Men: $9.2 \%$
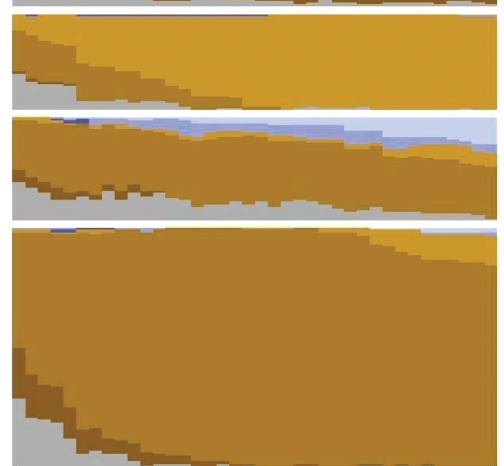

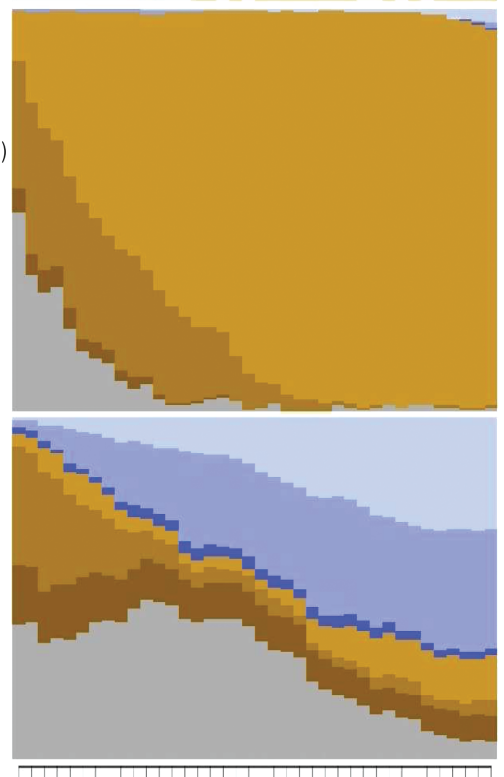

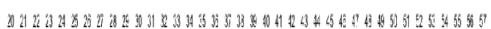

out of the labor force

full-time employment no pension investments

(1) pension fund

-

part-time employment, no pension investments

part-time employment, investment public pension fund

part-time employment, investments public and other pension funds
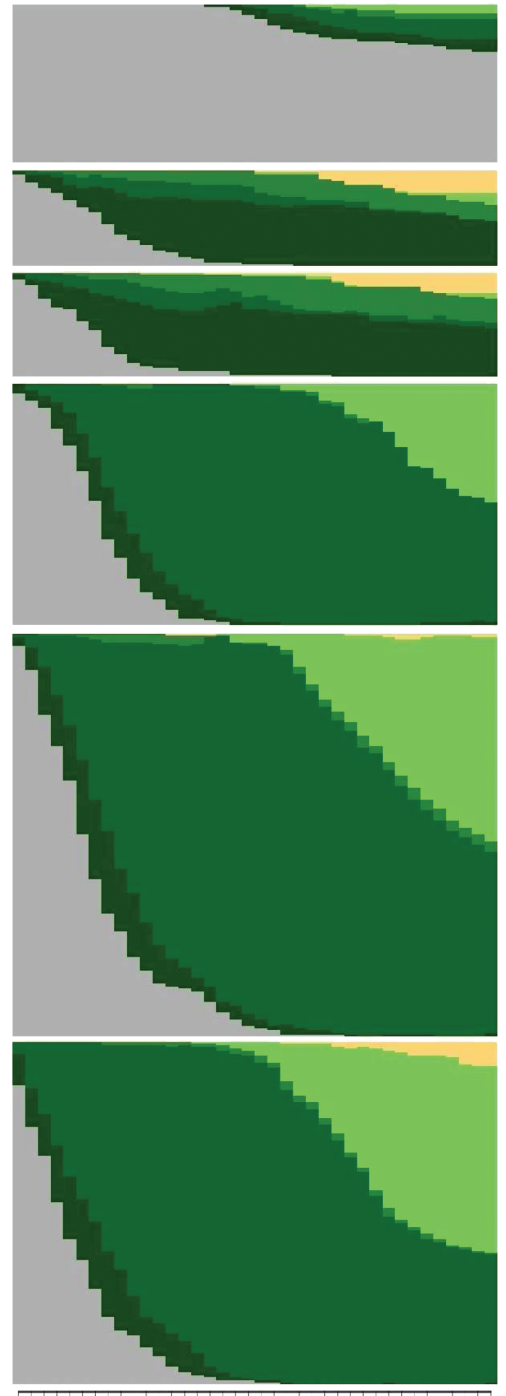

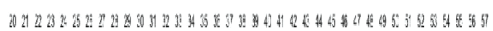

$\square$ single

married, no children

married, children

divorced

married plus departure of children from parental home

divorced plus departure of children from parental home

Figure 3. Six types of employment-family trajectories from age 20 to 57 in Switzerland.

and pension investments are made up of $85 \%$ men, the type including extended periods out of the labor force or part-time employment with pension investments, is made up of $90 \%$ women. The other three types (Types 4, 5, and 6) constitute rather small groups-between $12 \%$ and $7.4 \%$ of the sample population - and they are characterized by a family trajectory that deviates from the standard male-breadwinner-femalecaretaker model: divorced, childless marriage, and people who were never married.

Specifically, the first type is named "(1) Out of the labor force \& part-time worker, AVS + / children family” (share $=27.5 \%$, women $=90.8 \%$ men $=9.2 \%$ ). This type is mainly composed of women whose employment-family trajectories are characterized by being out of the labor market or in part-time jobs, investing both in the public and other pension funds, and simultaneously getting married and having children. The second type is called "(2) full-time worker, AVS+ / children family" ( share $=28.6 \%$, women $=7.2 \%$ men $=92.8 \%$ ), and is principally composed of men who have the same family trajectory as the previous type; however, in employment terms it is notably characterized by full-time employment and pension investments in the public and other pension funds, which fits strongly the hypothesis 3 .

The third type, entitled "(3) full-time worker, AVS / children family" $($ share $=16.8 \%$, women $=15.4 \%$ men $=84.6 \%)$, is also a male type but the main difference with Type 2 is that individuals have only invested pension savings in the frame of the public pension fund. Moreover, the fourth type named "(4) full-time and part-time workers, AVS / divorced” ( share $=7.7 \%$, women $=59.6 \%$ men $=40.4 \%$ ), 
grouped those individuals who worked either in full-time or parttime jobs, investing only in the public pension fund, and who in parallel get divorced. Finally, the fifth and the sixth types entitled respectively "(5) full-time worker, AVS + / divorced" (share $=7.4 \%$, women $=18.8 \%$ men $=81.3 \%)$ and " $(6)$ full-time worker, AVS+ / single" ( share $=12.0 \%$, women $=47.4 \%$ men $=52.6 \%$ ), gather people mostly in full-time jobs with opportunities to invest in different pension funds, who simultaneously either divorced or never married or had children.

The six types of interlocked employment-family trajectories are named based on the cumulative employment and family status of the majority of people in each group (Here is important to note that trajectory types (4) and (5) show also a great proportion of married people without children who later on get divorced.). Table 2 provides, among others descriptive information of these six types, an overview of the mean duration spent of each employment and family state in all the types mentioned.

\section{Discrete Time Models of Retirement Timings}

In each discrete time model we start by measuring the influence of control covariates, and then in a second model we add the types of interlocked employment-family trajectories to examine whether they provide additional significant results on retirement timing variation. We use the employment-family type "(2) full-time worker, AVS+ / children family" as reference category, as this type fits the most normative labor and family patterns. In this way we can evaluate the effect of groups that deviate from this traditional life course path (Table 1A shows, nevertheless, discrete time models of retirement timings using the other five employment-family types as reference category). Then, in order to demonstrate the importance of examining the effect of longterm employment and family trajectories on retirement timing instead of simply analyzing the work and family status at the time-point just before retirement, in a third model we adjust the results by the effect of employment and marital statuses during the year of retirement.

Explanations of models are rather descriptive because in the Discussion section they are problematized in the light of our research hypotheses. Moreover, it is important to mention that by means of the variance inflation factors - usually called "VIF coefficient" (Mansfield \& Helm, 1982) - multicollinearity among covariates was controlled, and only those covariates not showing high collinearity were used in models. Also, in the case of the on-time retirement model we do not adjust the results by age since this model only includes on-time retirement ages.

Table 3 shows the results of discrete time models on early, on-time, and late retirement. We observe particularly in Model 2 of early retirement (third column of Table 3 ) that individuals belonging to types "(1) out of the labor force \& part-time worker, AVS+ / children family" and "(3) full-time worker, AVS / children family" are less likely to retire early than the reference group. In Model 3 of early retirement, however, the significant effect of the type (1) is caught by the covariate "part-time job just before retirement." Nevertheless, Model 3 corresponds to a slightly worse model than Model 2 in terms of the AIC criterion; consequently this effect has to be analyzed carefully. Moreover, Model 2 and Model 3 of early retirement indicate that those who experienced more periods of ill-health during their careers tend to retire early from the labor market. We also note in both models that the older an individual is, the higher becomes the probability of retiring early-although it is important to remember that this model includes people subject to the risk of early retirement, so "oldest individuals" here means persons close to the state pension age. Furthermore, the same models indicate that individuals who experienced periods of financial hardship during the life course are less likely to experience early retirement.

In Models 2 and 3 of on-time retirement (sixth and seventh column of Table 3 ), we basically see that retirement at the state pension age is less frequent among individuals belonging to the types "(3) full-time worker, AVS / children family," "(4) full-time and part-time workers, AVS / divorced," and "(5) full-time worker, AVS+ / divorced.” Besides, people with a high educational background are less liable to on-time retirement. By contrast, men have a great propensity to retire "on-time."

Finally, Models 2 and 3 of late retirement (ninth and tenth column of Table 3), illustrate that people belonging to the type "(4) fulltime and part-time workers, AVS / divorced" tend to retire late from the labor market. Also, particularly in Model 3 of late retirement, we observe that whereas people grouped in type "(6) full-time worker, AVS+ / single" are more likely to postpone the retirement beyond the legal age, people whose marital status at retirement was "single" are less likely to late retirement. However, both effects have to be clarified first by the fact that when we measure the impact of the marital status "single" on late retirement in Model 1 -i.e., excluding from the regression the trajectory type "(6) full-time worker, AVS+ / single"-the marital status "single" show a positive effect on postponing retirement. In the opposite case, if we exclude from the model the marital status "single"-Model 2 - trajectory type (6) has a positive but nonsignificant effect on late retirement. Consequently, we can argue that the results shown by these two covariates in Model 3 of late retirement is rather a consequence of artificial estimation caused by a suppression effect (Conger, 1974).

In addition, we observe in Models 2 and 3 of late retirement that people who experienced financial difficulties during the life course also tend to depart late from the work sphere. By contrast, the same models indicate that individuals with the highest educational backgrounds are clearly not likely to retire late.

\section{DISCUSSION}

At the beginning of the Results section, an exploratory survival model showed that in Switzerland current retirement ages both for women and men are relatively linked to the state pension age, which confirms a moderate institutionalization of this transition. Nevertheless, by using discrete time modeling, we displayed the influence of employment and family trajectories on different retirement timings, demonstrating evidences of how accumulated statuses both in the work and family domains lead to a large variation in the timing of retirement.

We observed first that activity rates and family responsibilities play together a significant role in the retirement timing. Individuals who were out of the labor market long-term and simultaneously focused on family tasks such as childcare, and then come back to the labor market mostly in part-time jobs, are less likely to retire early and more likely to retire late (see types "(1) out of the labor force \& part-time worker, AVS+ / children family" and "(4) full-time and part-time workers, AVS / divorced”). These results corroborate in particular our hypothesis 1 and hypothesis 4. Indeed, although most of the people who 


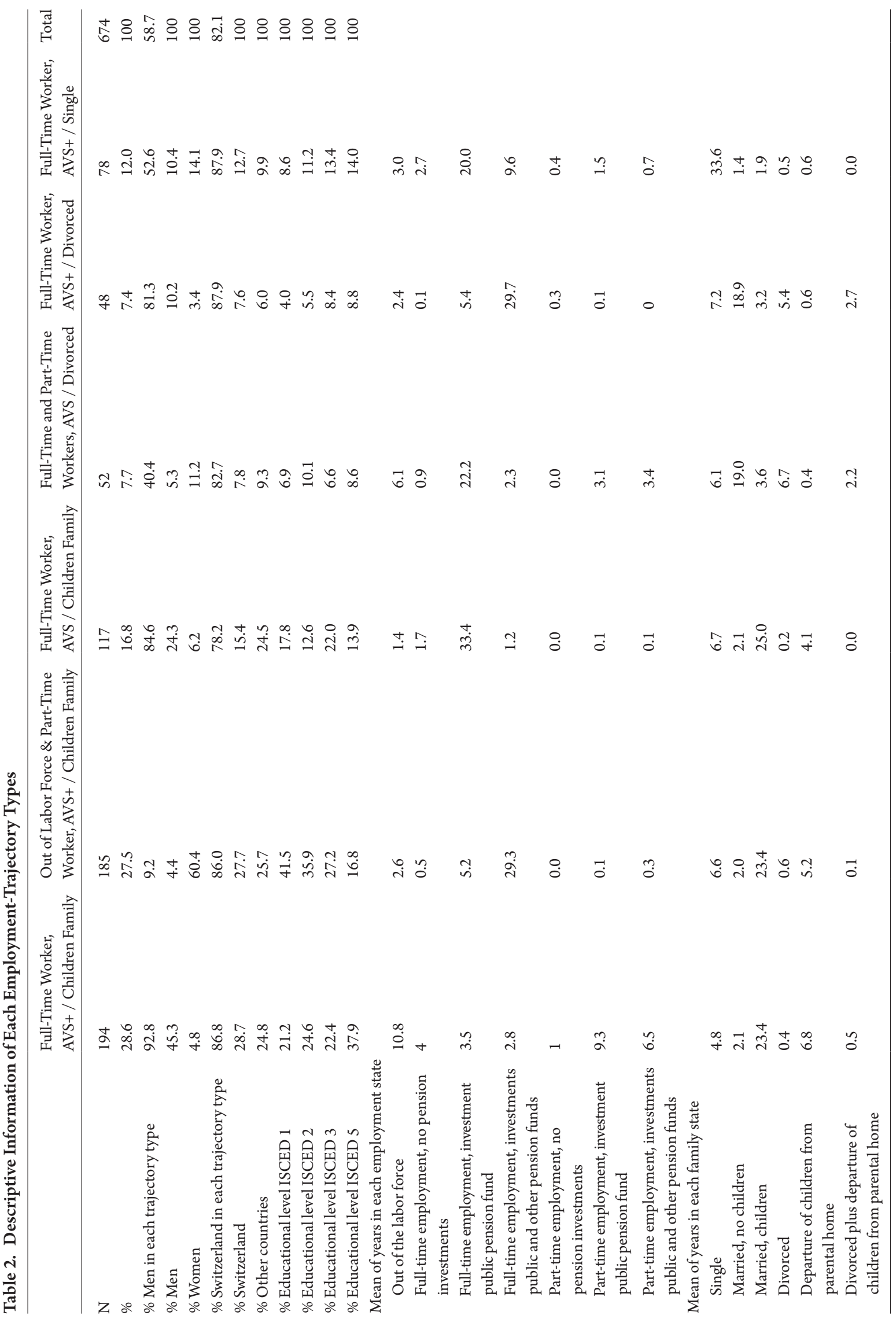


Table 3. Discrete Time Models for Early Retirement, "On-Time” Retirement, and Late Retirement (Dependent Variable: 1: Yes, 0: No. Coefficients in Odds Ratios)

\begin{tabular}{|c|c|c|c|c|c|c|c|c|c|}
\hline & \multicolumn{3}{|c|}{ Early Retirement } & \multicolumn{3}{|c|}{ On-Time Retirement } & \multicolumn{3}{|c|}{ Late Retirement } \\
\hline & Model 1 & Model 2 & Model 3 & Model 1 & Model 2 & Model 3 & Model 1 & Model 2 & Model 3 \\
\hline Key covariates & - & - & - & - & - & - & - & - & - \\
\hline $\begin{array}{l}\text { Full-time worker, AVS+ / } \\
\text { children family (reference) }\end{array}$ & - & - & - & - & - & - & - & - & - \\
\hline $\begin{array}{l}\text { Out of labor force \& part-time } \\
\text { worker, AVS+ / children family }\end{array}$ & - & $0.57^{*}$ & 0.72 & - & 0.59 & 0.79 & - & 0.82 & 0.73 \\
\hline Full-time worker, AVS / children family & - & $0.50^{* *}$ & $0.49^{* *}$ & - & $0.40^{*}$ & $0.39^{*}$ & - & 0.39 & 0.37 \\
\hline $\begin{array}{l}\text { Full-time and part-time workers, } \\
\text { AVS / divorced }\end{array}$ & - & 0.67 & 0.70 & - & $0.35+$ & $0.26^{*}$ & - & $3.40+$ & $3.53+$ \\
\hline Full-time worker, AVS+ / divorced & - & 0.81 & 0.78 & - & $0.33+$ & $0.27+$ & - & 0.39 & 0.43 \\
\hline Full-time worker, AVS+ / single & - & 0.89 & 0.79 & - & 0.72 & 0.97 & - & 2.41 & $8.83^{*}$ \\
\hline Control covariates & - & - & - & - & - & - & - & - & - \\
\hline Women (reference) & - & - & - & - & - & - & - & - & - \\
\hline Men & 0.83 & 0.90 & 0.78 & $2.22^{*}$ & $3.01^{*}$ & $2.56+$ & 0.61 & 0.74 & 0.58 \\
\hline Age & $1.41^{* * *}$ & $1.42^{* * *}$ & $1.42^{* * *}$ & - & - & - & 0.94 & 0.94 & 0.95 \\
\hline Ill health periods & $2.25^{* *}$ & $2.22^{* *}$ & $2.31^{* * *}$ & 1.30 & 1.48 & 1.66 & 1.45 & 1.44 & 1.69 \\
\hline Educational level ISCED 1 (reference) & - & - & - & - & - & - & - & - & - \\
\hline Educational level ISCED 2 & 1.08 & 1.04 & 1.03 & 0.73 & 0.72 & 0.72 & 0.73 & 0.59 & 0.66 \\
\hline Educational level ISCED 3 & 1.34 & 1.42 & 1.35 & $0.33^{* *}$ & $0.43+$ & $0.37^{*}$ & $0.38^{*}$ & $0.40^{*}$ & $0.40^{*}$ \\
\hline Educational level ISCED 5 & 1.40 & 1.31 & 1.28 & 0.63 & 0.59 & 0.55 & $0.33^{*}$ & $0.34^{*}$ & $0.37+$ \\
\hline Log (income) & 1.01 & 1.01 & 1.01 & 1.01 & 1.02 & 1.02 & 1.01 & 1.03 & 1.03 \\
\hline Financial hardship periods & $0.71+$ & $0.72+$ & $0.71+$ & 0.80 & 0.82 & 0.74 & $2.25^{*}$ & $2.80^{* *}$ & $2.67^{* *}$ \\
\hline Other countries (reference) & - & - & - & - & - & - & - & - & - \\
\hline Switzerland & 1.07 & 1.04 & 1.03 & 0.99 & 1.05 & 1.04 & 1.48 & 1.02 & 1.08 \\
\hline \multicolumn{10}{|c|}{ Employment and family conditions at retirement } \\
\hline $\begin{array}{l}\text { Marital status at retirement } \\
\text { (reference: married) }\end{array}$ & - & - & - & - & - & - & - & - & - \\
\hline Single & 1.24 & - & 1.19 & 0.96 & - & 0.65 & $2.38^{*}$ & - & $0.19+$ \\
\hline Divorced & 1.01 & - & 1.00 & 1.04 & - & 1.64 & 1.67 & - & 0.67 \\
\hline Widowed & 0.69 & - & 0.68 & 0.52 & - & 0.47 & 0.64 & - & 0.72 \\
\hline $\begin{array}{l}\text { Employment status just before } \\
\text { retirement (reference: full-time job) }\end{array}$ & - & - & - & - & - & - & - & - & - \\
\hline Part-time job & $0.59^{*}$ & - & $0.60+$ & 0.61 & - & 0.53 & 1.10 & - & 0.98 \\
\hline Constant & $0.00^{* * *}$ & $0.00^{* * *}$ & $0.00^{* * *}$ & 1.48 & 1.37 & 2.01 & 13.26 & 10.39 & 8.48 \\
\hline AIC & 1299.1 & 1296.6 & 1299.4 & 317.3 & 315.5 & 318.3 & 367.8 & 356.3 & 360.0 \\
\hline Observations & 3112 & 3112 & 3112 & 273 & 273 & 273 & 564 & 564 & 564 \\
\hline
\end{tabular}

Note. Significant coefficients in grey $\left({ }^{* * *} p<.001,{ }^{* *} p<.01 ;{ }^{*} p<.05 ;{ }^{+} p \leq .10\right)$.

worked in part-time positions or who faced unemployment periods worked earlier in life in full-time jobs, the weak labor force participation in transversal terms possibly yielded very few opportunities to invest in pension funds (for unemployed people), or not enough salary to invest substantially in savings for retirement (in the case of part-time workers).

Likewise, we observe that workers only investing in the public pension plan tend neither to retire early nor at state pension age (see type "(3) full-time worker, AVS / children family"), but rather to retire late (see type "(4) full-time and part-time workers, AVS / divorced"). Thus, the absence of chances to invest significantly in other pension funds besides the public one clearly may result in limited savings for departing from the labor market earlier (Hypothesis 2). We assume that this is particularly the case in liberal pension systems like Switzerland's, where occupational and private savings-which are completely dependent on own income-represent an important source of pension during elderly life (Bonoli, 2006).

Considering the types of joint employment-family trajectories not associated with standard family patterns-notably divorced people from trajectory types (4) and (5) who remained permanently in that marital status, and single people from trajectory type (6) -we observe that, independently of their employment trajectory, all of them are negatively associated with on-time retirement, and two of them-types (4) and (6) - are positively associated with late retirement (Hypothesis 6). Indeed, taking into consideration the results presented in Table 1A, when type "(4) full-time and part-time workers, 
AVS / divorced" is used as the reference category for regression models, almost all the other trajectory groups have fewer chances to retire late. Similarly, Table 1A show us that another group that deviates from standard family patterns (i.e., "(6) full-time worker, AVS+ / single") when is used as reference category in regression models, almost every trajectory group is less likely to postpone the retirement beyond the state pension age. Hence, as previous literature suggests, divorced and single individuals are less likely to retire early from the labor market because of reduced financial resources associated with the absence of their partner (Cherlin, 2009; Finch, 2014).

Moreover, people confronting illnesses during their careers are more likely to retire early, which has been traditionally explained as a consequence of their inability to continue working (Bazzoli, 1985). By contrast, we observed that individuals characterized by having financial difficulties are less likely to retire early and more likely to retire late. As some research indicates (Dorn \& Sousa-Poza, 2004a; Gowan, 1998) workers who have financial difficulties during their life need to remain active in the labor market to compensate for the lack of financial resources provided by the pension funds.

Furthermore, we noted that men tend more than women to retire at the state pension age. A plausible reason for the positive effect of being men who retire "on time," as previous research indicates, is the quasisystematic continuous careers of men (Han \& Moen, 1999; MaderoCabib, 2015), through which they can contribute continuously to different pension funds and have the means to retire at the state pension age and not later. Finally, on-time retirement and late retirement in Switzerland seem not to be options much taken by people with high educational background. Possibly, people with tertiary degrees find more opportunities to have full-time and well-paid jobs, which are traditionally associated with greater opportunities to accumulate appropriate pension resources for elderly life. As a consequence, they would not have to remain active after the state pension age.

\section{IMPLICATIONS AND FUTURE DIRECTIONS}

In this article, we have analyzed the transition from occupation to retirement, particularly the time frame in which people retire, that is early, ontime, or late retirement. We have focused on Switzerland, a country with a liberal pension structure that institutionally provides flexible mechanisms in terms of retirement timings. Considering a life course approach, our main objective was to analyze how long-term trajectories during early and middle adulthood (from age 20 to 57) influence the probability of retiring from age 58 onwards. The life course approach thus allowed us to go beyond the emphasis of classical retirement studies on the impact of snapshots characteristics of individuals just before retirement.

In this research, we focus specifically on two types of adulthood trajectories: employment and family life courses. Also, acknowledging the strong interrelation of work and family paths in current societies (Elder, 1985; Krüger \& Levy, 2001) we constructed interlocked types of employment and family trajectories. To this end we focused on the statuses activity rate and pension investments to make employment trajectories, and on the parenthood and marital statuses to build family trajectories.

Given our interest in investigating the retirement process in the light of the CAD approach, we would like to conclude this study considering the implication of accumulated and interlocked experiences in the family and work domains. We can affirm first that the longitudinal approach used in this research makes clear the importance of investigating more than just the impact of employment and family conditions at the retirement period. Indeed, we have demonstrated that even under the control of the employment and marital statuses at the moment of retirement, long-term life trajectories of individuals both in the employment and the family domains have a great influence on retirement timings, showing evidences thus about how accumulated life experiences impact on later life processes.

Moreover, our results allow us to recognize the advantage of analyzing the effect of interlocked (instead of separated) employment and family trajectories on the retirement process. By means of this methodological approach, we have firstly demonstrated the strong link between activity rate and family tasks as well as their high influence on retirement timing, both for men and women. Family trajectories characterized by early marriage and childbirth do not represent an obstacle for men to have employment life courses with full-time jobs and investments in public or private pensions. By contrast, for women, a highly similar family trajectory leads to career interruptions, part-time positions, and few chances to invest in private pension funds. As we have shown, these female employment-family paths are those with much less opportunity to retire earlier from the labor market.

Also, thanks to the focus on interlocked employment-family trajectories, we have been able to provide evidence about how family states such as divorce or being single seem to be a clear obstacle to retiring early from the labor market, regardless of whether the occupational trajectories of divorced and single individuals are characterized by fulltime or part-time jobs, or by pension investments only in the public pension fund or additionally in private pension funds.

Furthermore, the results show that the individual heterogeneity in retirement timings explained by stratification covariates indicates a mediation of social status on the retirement process. It has been illustrated that early and on-time retirement is more frequent among men, persons with higher educational backgrounds, people who did not confront periods of financial hardship, and finally individuals who can systematically invest in public and private pension funds. In this sense, late retirement apparently seems to be confronted mostly by individuals who during their life courses accumulated underprivileged characteristics for the late work period. Among those characteristics are not having the economic support of a partner, having family or work at home responsibilities, having financial difficulties, and the absence of chances to invest in specific pension funds, as occurs with people with long-term periods out of the labor market.

Ultimately, these socially differentiated dynamics toward the transition to retirement would indicate that the liberal and flexible Swiss retirement institution has insufficient mechanisms to promote socially homogeneous withdrawals for older individuals. Indeed, one might argue that the current pension system is more favorable to individuals with higher social status as they currently have greater opportunities to depart early from the occupational sphere. In this sense, the Swiss retirement institution should consider alternative mechanisms to offer more balanced retirement opportunities to its citizens, especially to those following less advantaged trajectories. For instance, one way to alleviate immediate gender gaps is to improve ex-post recognition of family care over the life course in pension accrual, which was recently introduced in the Swiss pension systems with additional pension points for each child a woman had (CFQF, 2011). 
The findings presented in the current article contribute to the literature on retirement by providing evidence about the influence of life course factors such as employment and family long-term trajectories. They offer an original perspective on and many opportunities to explore the way forward on the transition to retirement. However, there are undoubtedly certain limitations in this research. In particular, two are the main substantive aspects of this study that could be more accurately investigated.

First, as already noted, Switzerland presents a gendered life course regime, which basically implies strong male-breadwinner orientations in the Swiss labor and family domains. As consequence, the vast majority of the women included in the Swiss component of SHARELIFE probably followed a traditional family trajectory, for example, marriage and children's births, which could forced them to confront either extended periods out of the labor force or definitively leave the labor force early in life. Given that in this research we only considered the retirement process for those following a career after age 58, we possibly leave out all those people-mainly women-who due to family responsibilities never worked or stopped working before age 58 and never returned to the labor market. Therefore, prospective investigations could also provide information on the retirement transition of those many women who, mainly because of family tasks, retire informally from the labor market many years before age 58 .

Secondly, further research could also bring better insight into the life situations of the individuals with whom the respondents live. In life course studies, this theoretical topic have been called the linked-lives approach (Moen, 2003), and basically stresses the fact that the life courses of family members are closely synchronized with one another, first, in terms of the timing of life transitions, and secondly, in the types of those life transitions. In this respect, although the empirical analyses in the current study have considered the impact of marital and parental statuses, there are various aspects of the fact of living with relatives and nonrelatives that could be developed in further studies. One of these aspects concerns the link between wife's and husband's trajectories across the life course. For example, it would be interesting to know if the low pension income of women who during their lives worked mainly in part-time positions has an effect on their husbands' obligation to continue working after the state pension age. Moreover, while the effect of divorce was controlled for in all the regression models, the specific effect of pension splitting between couples in the event of divorce was not considered. Hence, additional studies could integrate the moderating effect that the division of pensions for divorced individuals might have on, for instance, retirement timings. Finally, another aspect of the linked-lives approach that should be considered for the study of retirement transitions relates to the old-age conditions of the worker's partner, notably occupational, retirement, and health conditions.

\section{ACKNOWLEDGMENTS}

We wish to thank to Prof. Dr. Anette Fasang and Prof. Dr. Dirk Hofäcker for their valuable orientation to carry out this article. This research has been financed by the NCCR LIVES Project, of the Swiss National Foundation of Science (FNS).

\section{REFERENCES}

Abbott, A. (1995). Sequence analysis: New methods for old ideas. Annual Review of Sociology, 21, 93-113.
Allison, P. (1982). Discrete-time methods for the analysis of event histories. Sociological Methodology, 13, 61-98.

Bazzoli, G. (1985). The early retirement decision: New empirical evidence on the influence of health. Journal of Human Resources, 20, 214-234.

Beehr, T., \& Bennett M. (2015). Working after retirement: Features of bridge employment and research directions. Work, Aging and Retirement, 1, 112-128.

Bonoli, G. (2006). Switzerland: The impact of direct democracy. In E. Immergut, K. Andersom \& I. Schulze (Eds.), The handbook of west European pension politics (pp. 203-247). New York: Oxford University Press.

Calvo, E., Bertranou, F. M., \& Bertranou, E. (2010). Are old-age pension system reforms moving away from individual retirement accounts in Latin America? Journal of Social Policy, 39, 223-234.

Candolfi, P., \& Chaze, J. P. (2008). Impact de la retraite anticipée sur les cotisations et les prestations de l'AVS. Suisse: Laboratoire d'économie appliqué, Université de Genève.

Cattacin, S. (2006). Retard, rattrapage, normalisation. L'Etat social suisse face aux défis de transformation de la sécurité sociale. Studien und Quellen, 31, 49-78.

CFQF. (2011). Femmes $\mid$ pouvoir $\mid$ histoire politique de l'égalité et des questions féminines en Suisse. Suisse: Département fédéral de l'intérieur.

Cherlin, A. (2009). Marriage, divorce, remarriage. Cambridge, MA: Harvard University Press.

Conger, A. (1974). A revised definition for suppressor variables: A guide to their identification and interpretation. Educational and Psychological Measurement, 34, 35-46.

Damman, M., Henkens, K., \& Kalmijn, M. (2011). The impact of midlife educational, work, health, and family experiences on men's early retirement. The Journals of Gerontology, Series B: Psychological Sciences and Social Sciences, 66, 617-627.

Dannefer, D. (2003). Cumulative advantage/disadvantage and the life course: Cross-fertilizing age and social science theory. The Journals of Gerontology, Series B: Psychological Sciences and Social Sciences, 58, 327-337.

Deville, J., \& Särndal, C. (1992). Calibration estimators in survey sampling. Journal of the American Statistical Association, 87, 376-382.

DiPrete, T., \& Eirich, G. (2006). Cumulative advantage as a mechanism for inequality: A review of theoretical and empirical developments. Annual Review of Sociology, 32, 271-297.

Dorn, D., \& Sousa-Poza, A. (2004a). Motives for early retirement: Switzerland in an international comparison. Working Paper No. 99, Department of Economy, University of Saint Gallen.

Dorn, D., \& Sousa-Poza, A. (2004b). The determinants of early retirement in Switzerland. Working Paper No. 98, Department of Economy, University of Saint Gallen.

Elder, G. (1985). Perspectives on the life course. In G. Elder (Ed.), Life course dynamics: Trajectories and transitions, 1968-1980 (pp. 23-49). New York: Cornell University Press.

Elder, G. (1995). The life course paradigm: Social change and individual development. In P. Moen, G. H. Elder, \& K. Luscher (Eds.), Examining lives in contexts: Perspectives on the ecology of human development (pp. 101-139). Washington, DC: American Psychological Association.

Esping-Andersen, G. (2011). Pensions at a glance 2011: Retirementincome systems in OECD and G20 countries. Paris, France: OECD Publishing. 
Fasang, A. E., Aisenbrey, S., \& Schömann, K. (2013). Women's retirement income in Germany and Britain. European Sociological Review, 29, 968-980.

Finch, N. (2014). Why are women more likely than men to extend paid work? The impact of work-family life history. European Journal of Ageing, 11, 31-39.

Fraccaroli, F., \& Deller, J. (2015). Work, aging, and retirement in Europe: Introduction to the special issue. Work, Aging and Retirement, 1, 237-242.

Gabadinho, A. Ritschard, G., Müller, N., \& Studer, M. (2011). Analyzing and visualizing state sequences in $\mathrm{R}$ with TraMineR. Journal of Statistical Software, 40, 1-37.

Gaillard, G., Bilger, M., Candolfi, P., Chaze, J.-P., \& Flückiger, Y. (2003). Analyse des déterminants individuels et institutionnels du départ anticipé à la retraite. Suisse: Université de Genève Laboratoire d'économie appliquée.

Gauthier, J. A., Widmer, E. D., Bucher, P., \& Notredame, C. (2010). Multichannel sequence analysis applied to social science data. Sociological Methodology, 40, 1-38.

Gobeski, K., \& Beehr, T. (2009). How retirees work: Predictors of different types of bridge employment. Journal of Organizational Behavior, 30, 401-425.

Gowan, M. (1998). A preliminary investigation of factors affecting appraisal of the decision to take early retirement. Journal of Employment Counseling, 35, 124-140.

Han, S., \& Moen, P. (1999). Clocking out: Temporal patterning of retirement. American Journal of Sociology, 105, 191-236.

Hamblin, K. (2010). Changes to policies for work and retirement in EU15 nations (1995-2005): An exploration of policy packages for the 50-plus cohort. International Journal of Ageing and Later Life, 5, 13-43.

Hanel, B. (2010). Financial incentives to postpone retirement and further effects on employment-Evidence from a natural experiment. Labour Economics, 17, 474-486.

Hank, K., \& Korbmacher, J. (2013). Parenthood and retirement. Gender, cohort, and welfare regime differences. European Societies, 15, 446-461.

Kohli, M., Rein, M., Guillemard, A.-M., \& Van Gunsteren, H. (1991). Time for retirement: Comparative studies of early exit from the labor force. Cambridge: Cambridge University Press.

Krüger, H., \& Levy, R. (2001). Linking life courses, work, and the family: Theorizing a not so visible nexus between women and men. Canadian Journal of Sociology, 26, 145-166.

Kuehni, M., Rosende, M., \& Schoeni, C. (2013). Maintien en emploi et inégalités de sexe. Lien social et Politiques, 69, 197-213.

Lesnard, L. (2010). Setting cost in optimal matching to uncover contemporaneous socio-temporal patterns. Sociological Methods \& Research, 38, 389-419.

Le Feuvre, N., Kuehni, M., Rosende, M., \& Schoeni, C. (2014). Le Genre du "vieillissement actif": du principe du traitement équitable à la multiplication des injonctions contradictoires. Swiss Journal of Sociology, 40, 307-324.

Lumley, T. (2013). Survey: Analysis of complex survey samples. $R$ package version 3.28-2.

MacIndoe, H., \& Abbott, A. (2004). Sequence analysis and optimal matching techniques for social science data. In M. Hardy \& A. Bryman (Eds.), Handbook of data analysis (pp. 387-406). London: Sage Publications.
Madero-Cabib, I. (2015). The life course determinants of vulnerability in late careers. Longitudinal and Life Course Studies, 6, 88-106.

Madero-Cabib, I., \& Kaeser, L. (in press). How voluntary is the active aging life? A life-course study on the determinants of extending careers. European Journal of Ageing.

Mansfield, E., \& Helms, B. (1982). Detecting multicollinearity. The American Statistician, 36, 158-160.

Mills, M. (2011). Introducing survival and event history analysis. Thousand Oaks, CA: Sage.

OECD. (2012). OECD pensions outlook 2012. Paris, Paris: OECD Publishing.

OFS. (2011). Indicateurs de la prévoyance vieillesse, résultats des indicateurs clés. Suisse: Département fédéral de l'intérieur.

OFS. (2012a). Rentes de vieillesse et allocations pour impotent de l'AVS. Suisse: Centre d'information AVS/AI.

OFS. (2012b). Newsletter No 1 information demographiques. Suisse: Département fédéral de l'intérieur.

OFS. (2012c). Cotisations à l'AVS, à l'AI et aux APG. Suisse: Centre d'information AVS/AI.

OFS. (2012d). La sécurité sociale en Suisse. Suisse: Centre d'information AVS/AI.

OFS. (2014). Obligation de s'affilier à une institution de prévoyance conformément à la LPP. Suisse: Centre d'information AVS/AI.

$\mathrm{R}$ Core Team. (2012). R: A language and environment for statistical computing. Vienna, Austria: R Foundation for Statistical Computing. Retrieved August 6, 2015, from www.R-project.org

Raymo, J. M., Warren, J. R., Sweeney, M. M., Hauser, R. M., \& Ho, J. H. (2011). Precarious employment, bad jobs, labor unions, and early retirement. The Journals of Gerontology, Series B: Psychological Sciences and Social Sciences, 66, 249-259.

Reynolds, F., Farrow, A., \& Blank, A. (2012). Otherwise it would be nothing but cruises': Exploring the subjective benefits of working beyond 65. International Journal of Ageing and Later Life, 7, 79-106.

Roduit, G. (1993). Switzerland. International Social Security Review, 46, 75-81.

Schröder, M. (2011). Retrospective data collection in the Survey of Health, Ageing and Retirement in Europe. SHARELIFE Methodology. Mannheim: MEA.

Scruggs, L., \& Allan, J. (2006). Welfare-state decommodification in 18 OECD countries: A replication and revision. Journal of European Social Policy, 16, 55-72.

Stähli, M., \& Joye, D. (2013). New and emerging methods: Nonrespondent surveys: pertinence and feasibility. The Survey Statistician, 68, 16-22.

Studer, M. (2013). WeightedCluster library manual: A practical guide to creating typologies of trajectories in the social sciences with R. LIVES Working Papers, 24. Geneva, Switzerland: University of Geneva Institute for Demographic and Life Course Studies.

Tabin, J.-P. (2002). Les nouvelles régulations politiques de la question sociale: Illustrations en Suisse d'un phénomène global. Déviance et Societé, 26, 221-231.

Tabin, J.-P., Frauenfelder, A., Togni, C., \& Keller, V. (2008). Temps d'assistance. Le gouvernement des pauvres en Suisse romande depuis la fin du XIXe siècle. Suisse: Antipodes.

UNESCO. (2006). International standard classification of education. Retrieved August 6, 2015, http://www.uis.unesco.org/Library/ Documents/isced97-en.pdf 
van Oorschot, W., \& Jensen, P. (2009). Early retirement differences between Denmark and The Netherlands. A cross-national comparison of push and pull factors in two small European welfare states. Ageing Studies, 23, 267-278.

Wang, M. (2007). Profiling retirees in the retirement transition and adjustment process: Examining the longitudinal change patterns of retirees' psychological well-being. Journal of Applied Psychology, 92, 455-474.
Wang, M., Zhan, Y., Liu, S., \& Shultz, K. S. (2008). Antecedents of bridge employment: A longitudinal investigation. Journal of Applied Psychology, 93, 818-830.

Ward, J. (1963). Hierarchical grouping to optimize an objective function. Journal of American Statistical Association, 58, 236-244.

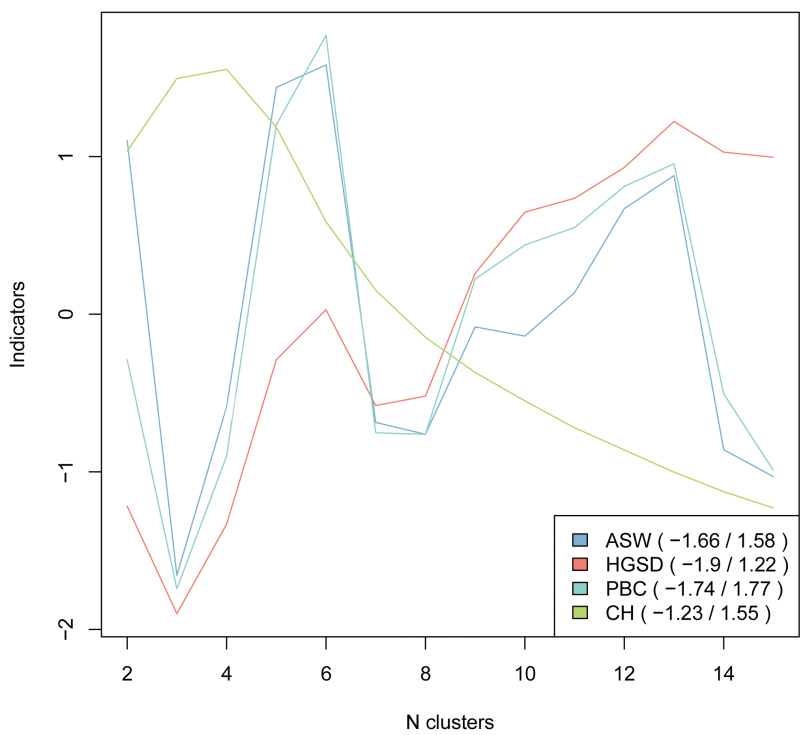

Appendix Figure 1. Cluster cut-off criteria for Ward cluster analysis on pairwise distance matrix obtained with multichannel sequence analysis. 
Appendix Table 2. Discrete Time Models for Early Retirement, “On-Time” Retirement, and Late Retirement, Using Different Trajectory Types as Reference Category

\begin{tabular}{|c|c|c|c|}
\hline & Early Retirement & On-Time Retirement & Late Retirement \\
\hline Key covariates & - & - & - \\
\hline Full-time worker, AVS+ / children family (reference) & - & - & - \\
\hline Out of labor force \& part-time worker, AVS+ / children family & 0.72 & 0.79 & 0.73 \\
\hline Full-time worker, AVS / children family & $0.49^{* *}$ & $0.39^{*}$ & 0.37 \\
\hline Full-time and part-time workers, AVS / divorced & 0.70 & $0.26^{*}$ & $3.53+$ \\
\hline Full-time worker, AVS+ / divorced & 0.78 & $0.27+$ & 0.43 \\
\hline Full-time worker, AVS+ / single & 0.79 & 0.97 & $8.83^{*}$ \\
\hline Out of labor force \& part-time worker, AVS+ / children family (reference) & - & - & - \\
\hline Full-time worker, AVS+ / children family & 1.40 & 1.26 & 1.38 \\
\hline Full-time worker, AVS / children family & 0.68 & 0.49 & 0.51 \\
\hline Full-time and part-time workers, AVS / divorced & 0.98 & $0.33+$ & $4.86^{* *}$ \\
\hline Full-time worker, AVS+ / divorced & 1.10 & 0.34 & 0.59 \\
\hline Full-time worker, AVS+ / single & 1.11 & 1.22 & $12.2^{* *}$ \\
\hline Full-time worker, AVS / children family (reference) & - & - & - \\
\hline Out of labor force \& part-time worker, AVS+ / children family & 1.46 & 2.03 & 1.96 \\
\hline Full-time worker, AVS+ / children family & $2.04^{* *}$ & $2.57^{*}$ & 2.70 \\
\hline Full-time and part-time workers, AVS / divorced & 1.43 & 0.67 & $9.53^{* * *}$ \\
\hline Full-time worker, AVS+ / divorced & 1.60 & 0.70 & 1.15 \\
\hline Full-time worker, AVS+ / single & 1.62 & 2.48 & $23.85^{* * *}$ \\
\hline Full-time and part-time workers, AVS / divorced (reference) & - & - & - \\
\hline Out of labor force \& part-time worker, AVS+ / children family & 1.02 & $3.05+$ & $0.21^{* *}$ \\
\hline Full-time worker, AVS+ / children family & 1.43 & $3.84^{*}$ & $0.28+$ \\
\hline Full-time worker, AVS / children family & 0.70 & 1.50 & $0.10^{* * *}$ \\
\hline Full-time worker, AVS+ / divorced & 1.12 & 1.04 & $0.12^{* *}$ \\
\hline Full-time worker, AVS+ / single & 1.14 & 3.71 & 2.50 \\
\hline Full-time worker, AVS+ / divorced (reference) & - & - & - \\
\hline Out of labor force \& part-time worker, AVS+ / children family & 0.91 & 2.92 & 1.70 \\
\hline Full-time worker, AVS+ / children family & 1.27 & $3.68+$ & 2.34 \\
\hline Full-time worker, AVS / children family & 0.62 & 1.43 & 0.87 \\
\hline Full-time and part-time workers, AVS / divorced & 0.89 & 0.96 & $8.26^{* *}$ \\
\hline Full-time worker, AVS+ / single & 1.01 & 3.55 & $20.69^{* *}$ \\
\hline Full-time, AVS+ / single (reference) & - & - & - \\
\hline Out of labor force \& part-time worker, AVS+ / children family & 0.90 & 0.82 & $0.08^{* *}$ \\
\hline Full-time worker, AVS+ / children family & 1.26 & 1.04 & $0.11^{*}$ \\
\hline Full-time worker, AVS / children family & 0.62 & 0.40 & $0.04^{* * *}$ \\
\hline Full-time and part-time workers, AVS / divorced & 0.88 & 0.27 & 0.40 \\
\hline Full-time worker, AVS+ / divorced & 0.99 & 0.28 & $0.05^{* *}$ \\
\hline
\end{tabular}

Note. Dependent variable: 1: Yes, 0: No. Coefficients in odds ratios. Coefficients of control covariates not shown here but every model is adjusted for both key and control covariates. Significant coefficients in grey $\left({ }^{* * *} p<.001,{ }^{* *} p<.01 ;{ }^{*} p<.05 ;{ }^{+} p \leq .10\right)$. 